countries. A programme covering the biology and distribution of Macrocystis aims at giving a reliable estimate of the quantity of this seaweed in Australian waters, the seasonal and long-term fluctuations in yield of the seaweed and its products, and the method of regeneration of the plant.

Food research included a detailed study of the performance of refrigerated railcars with end bunkers and coolers, which led to the preparation of a statement of the principles governing the use of these vehicles for chilled beef transport. An account of the work on the evaluation of canning processes was published. Studies of the temperature relations of Clostridium botulinium and of the factors affecting the germination of heat-treated bacterial spores continued, while much work was done on the development of rapid laboratory and field methods for estimating the degree of fish spoilage. The longer storage life of dehydrated sugared fruit compared with ordinary dehydrated fruit has been confirmed, and varieties of fruit and vegetables were being tested for suitability for freezing.

The anatomical studies of timbers from Malaya, Borneo and New Guinea have proved of considerable value, and attention has also been paid to the factors causing the death of medullary ray and vertical parenchyma cells in sapwood-heartwood. Activity in the wood preservation field markedly increased; a survey of the causes of failure of preservative treatment of cross-arms was completed in Western Australia, Victoria and New South Wales, and a laboratory study of the toxicity and permanence of water-borne preservatives was commenced. Research on the properties and uses of building materials continued in the Division of Building Research; but the only new project was the preparation of a paper on the weathering and durability of building materials in the tropics for the International Building Research Congress held in London in September 1951.

Wool textile research was extended to cover the improvement of wool as a textile fibre and the reduction of costs of production of woollen, worsted and felted materials, but several years must elapse before the new laboratories are fully staffed with adequately trained research workers. Considerable interest has been displayed in the two processes recommended by the Organization for the recovery of wool from sheepskin pieces and broken skins. A suitable method has been developed for the alkaline hydrolysis of wool wax to wax alcohols and acids, and the study of the formation of fibres under natural conditions has been continued in the Division of Industrial Chemistry, where much attention has also been given to the study of wool wax and sugarcane wax. Steps were taken to provide a more comprehensive microanalytical service for scientific institutions and industry. Attention was also being given to analytical problems in connexion with the uranium ores of South Australia, the chemistry of alunite and its utilization in the production of potash fertilizers, the physiologically active alkaloidal principle of the Dwalganup strain of subterranean clover, and to liquid and vapour equilibrium concentrations of binary mixtures and their variation with temperature or pressure, in relation to plant design. A satisfactory method of concentrating topaz (used in ceramic ware) has been devised. The Section of Physical Metallurgy was concerned mainly with the metallography of alloys of titanium, gas surface reactions of titanium, and the influence of prolonged stress on lead alloys.
The work of the Division of Tribophysics continued on the same lines as in the previous year, but was still hindered by lack of space; and that of the Division of Metrology was largely determined by its statutory responsibilities for Commonwealth standards. The Division of Physics was also concerned with research designed to improve the accuracy of the methods of maintenance of standards, to increase the accuracy of measurement, the determination of prcperties of materials at extremely low temperatures and the study of the physical processes associated with the emission of radiation from the sun, including the development of new techniques for the study of the ionosphere and improved navigational aids under Australian conditions. The work of the Section of Meteorological Physics was consolidated and extended on the previous lines, including the prevention of frosts in orchards, the physics of rain and clouds, and the artificial formation of rain. In the Section of Mathematical Statistics two further centres have been established to provide direct assistance to divisions of the Organization in their experimental work. The Organization continues to co-operate with the Physics Department of the University of Melbourne in research on nuclear physics and cosmic rays under the direction of Prof. L. H. Martin.

\section{AMERICAN SCIENTIFIC EQUIPMENT FOR BRITISH LABORATORIES}

$\mathrm{T}$

HE last report of the director of the Chemical Research Laboratory, 'Teddington, acknowledged the indebtedness of the Laboratory to the European Co-operation Administration of the United States for the supply of equipment unobtainable in Britain, including a Podbielniak Hyd-Robot self-recording low-temperature fractional-distillation unit, a Beckmann flame spectrophotometer and a multi-source unit for spectrographic work. A list of scientific equiprnent to the value of more than $£ 350,000$ made available in this way, chiefly to the Department of Scientific and Industrial Research, but also to some twenty-four other research institutions throughout the United Kingdom, has now been published*. The equipment, much of which is obtainable only in the United States, has been made available for a wide range of industries, and about three-quarters of it has already been received. It includes such diverse items as: an anderometer, enabling investigations to be made on precision bearings used in machine-tool spindles, etc., with the view of improving economy and quality of production; a compact surface analyser ; a 'Falex' lubricant tester; multi-channel directreading spectrographs permitting the use of methods much in advance of existing rapid analytical technique; and a high-temperature dilatometer for research into moulding sand.

The National Physical Laboratory has been supplied with a set of valves for the construction of instruments for calibration in the frequency-range $2,660-10,000 \mathrm{Mc}$./s., a Carey recording spectrophotometer, a thallium boron-iodide prism, $K$-band klystron oscillators and crystal detectors, and with 'Fosterite' photoelastic material, as well as with nine Berkeley decimal electronic counting units. The Building Research Station has received two American explosive-actuated fastening tools as well as a portable

* Issued by the Industrial Correspondent, Mutual Security Agency, American Embassy, Grosvenor Square, London, W.1. 
strain-indicator, while American 'trafficators' with magnetic counters and accessories will assist the Road Research Jaboratory in taking traffic censuses. The Fuel Research Station has received a centrifugal molecular still, a Brabender semi-automatic moisture tester, a temperature-compensated Worden gravity meter and deep-sounding gear; and a special disk of metals not available in Britain will assist the Gas Research Board in furthering its fluidized bed technique for gasifying coal. The development of heat pumps has been assisted by the supply of a special small thermostatic expansion-valve, and in connexion with the generation of electricity from wind power special transducer valves have been supplied for gust recorders.

A Franz isodynamic separator has been supplied for the magnetic separation of minerals used in the atomic energy programme, and a small high-pressure pilot plant for catalytic flow-through experiments in organic synthesis. 'I'he work of the Shirley Instituto has been facilitated by the installation of two SacoLowell speed frames and a ring frame, as well as a Scott serigraph for testing the strength of coarse yarns and light-weight fabrics. A special tensile testing instrument is being supplied to the Wool Industries Research Association, and a laboratorytype steamer, with pneumatically operated squeezerolls, to the Linen Industry Research Association. Other equipment supplied to research associations include the following : to the British Scientific Instrument Research Association, a Beckmann quartz spectrophotometer; the Motor Industry Research Association, a 'Stresscoat' equipment for stress analysis of crankshafts ; the Pest Infestation Laboratory, American methyl bromide applicators; the Leather Manufacturers' Research Association, a Beckmann ultra-violet spectrophotometer; and to the British Paint, Colour and Varnish Manufacturers' Research Association, equipment to modernize a Perkin-Elmer spectrograph, a set of diffraction reference cards, and an automatic mixer for pigments and various media.

\section{SURAMIN (BAYER 205) IN ANIMAL TISSUES}

\section{Demonstration of Bayer 205 (Suramin) in Tissues and its Cellular Distribution}

THE purpose of our investigations was the elaboration of a histological method suitable for the study of the microscopic localization of suramin. Such a procedure seemed all the more desirable as this important chemotherapeutic drug is also, from a general theoretical point of view, an extremely interesting compound, owing to its being closely linked to proteins and its extremoly long persistence in the organism (see refs. 1 and 2 for the literature).

Our experiments were based on the conception of combining the colourless sulphonic acid with a dye cation, thus rendering it visible. On the interaction of suramin and basic dyes in aqueous solution, coloured complexes are formed and, at a certain ratio of suramin to the dye, precipitation occurs, the same colloid ehemical rules being valid as in the case of the interaction of acid and basic dyes having opposite electric charges. Among the quinone dyes with closed rings, several were found which could be also combined with the suramin present in the cells.
Suramin could be 'stained' successfully with the following dyes: phenosafranin, cresyl blue, azure $B$ (trimethylthionin). The best result was, however, obtained with methylene blue eosinate, which stained the cytoplasmic granules containing suramin deep violet; the nuclei were also faintly stained, and the counter staining of the eosine became visible too.

The essence of the specific staining technique is that a methyl alcoholic dye solution is used for fixing and staining simultaneously and, in contrast with routine histological methods, water is not employed, only organic solvents. A membrane cut from the connective tissue, omentum or mosentery is quickly spread out by means of pins on a slide, and, before drying, May-Grünwald stain is poured over it and left until it has nearly evaporated; then it is differentiated with continuous agitation in absolute ethyl alcohol for 20-30 sec.; the differentiation is interrupted with xylene, and the preparation is thoroughly washed in xylene and mounted in copaiva balsam. Smears of blood or exudate can be similarly stained as well as kidney tissue smears, in which the localization of the suramin in the nephron can be followed to great distances.

A second method is to place small pieces of organs in excess of May-Grünwald solution for about $10 \mathrm{hr}$. and then transfer them directly into benzene and embed them in paraffin; afterwards the sections are floated on slides, deparaffinized and mounted in copaiva balsam (see photograph).

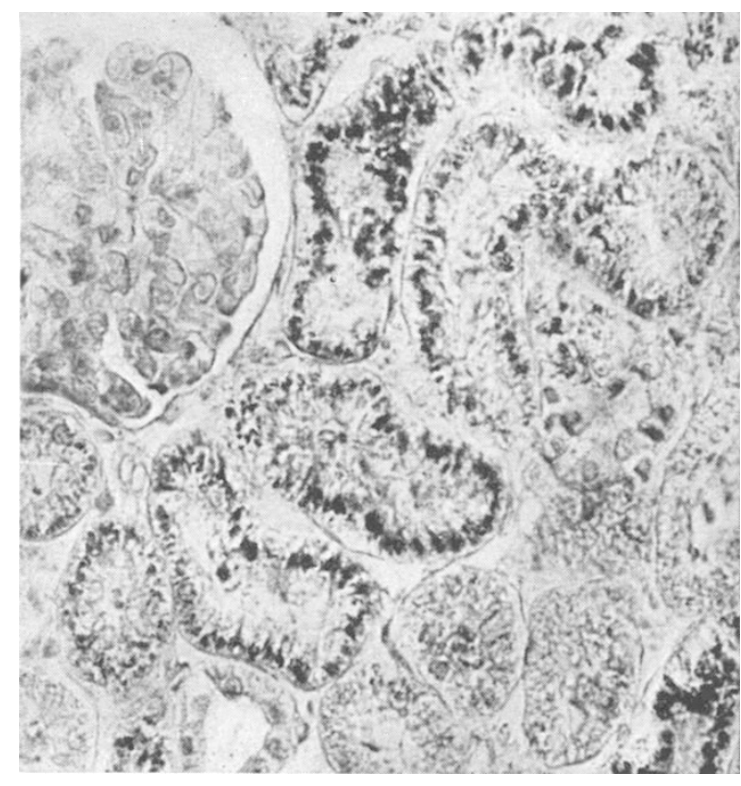

Rat kidney $72 \mathrm{hr}$, after intravenous injection of $20 \mathrm{mgm}$. suramin. Granules containing suramin in the epithelial cells of the proximal tubular segment

Our investigations, with mice, rats and guinea pigs treated with suramin, furnished evidence that the drug is ingested by reticulo-endothelial cells in which it accumulates, forming granules in the course of a few days. Suramin could also be detected in fibrocytes and serosal epithelial cells. It appears in the course of the first few hours in the epithelial cells of the proximal tubules of the kidney, and may be stored there in large amounts, being visible even after one or two months, inducing occasionally a nephrosis. Thus suramin behaves in the organism similarly to the vital acid dyes (for example, trypan blue) or the 